\title{
Bir diş hekimliği fakültesi ağız, diş ve çene cerrahisi kliniğine başvuran hastaların dental kaygı düzeylerinin değerlendirilmesi
}

\author{
Sara Samur Ergüven, ${ }^{1 *}$ Yeliz Kılınç, ${ }^{2}$ \\ Ertan Delilbaşı, ${ }^{2}$ Berrin Işık ${ }^{3}$

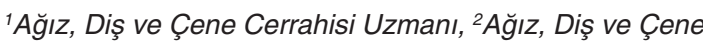 \\ Cerrahisi Anabilim Dalı, Gazi Üniversitesi Diş Hekimliği \\ Fakültesi, ${ }^{3}$ Anesteziyoloji ve Reanimasyon Anabilim Dalı, \\ Gazi Üniversitesi Tıp Fakültesi, Ankara, Türkiye
}

\section{ÖZet}

AmAÇ: Bu çalışmanın amacı, Ağız, Diş ve Çene Cerrahisi kliniğine başvuran hastaların dental kaygı düzeylerini belirlemek ve dental kaygının ilişkili olabileceği düşünülen faktörlerle olan bağlantısını değerlendirmektir.

Gereç ve Yöntem: Gazi Üniversitesi Diş Hekimliği Fakültesi Ağız, Diş ve Çene Cerrahisi Kliniğine 1 Şubat 20131 Ocak 2014 tarihleri arasında başvuran hastalara ( $n=1165)$ dental kaygı düzeyinin değerlendirilmesi amacıyla Modifiye Dental Anksiyete Skalası (MDAS) ve dental kaygının bağlantılı olabileceği düşünülen faktörlere ilişkin soruları içeren anketler uygulandı. MDAS skor değeri $\geq 19$ olan katılımcılar yüksek dental kaygı düzeyine sahip olarak değerlendirildi. Katılımcıların demografik özelliklerini de içeren veriler istatistik programına aktarılarak deskriptif yöntemler ile sonuçlar değerlendirildi.

BULGULAR: Çalışmaya katılan hastaların \%14.1'inde yüksek dental kaygı saptandı. Dental kaygı, cinsiyet, daha önce geçirilmiş travmatik deneyim varlığı ve diş hekimine gitme sıklığı ile ilişkili bulundu ( $p<0.05)$; ancak yaş, medeni durum, eğitim düzeyi, diş hekimine ilk gitme yaşı, eksik diş sayısı ve kliniğe başvuru amacı parametreleri ile ilişkili bulunmadı ( $p>0.05)$.

Sonuç: Bu çalışmanın sonuçları ağız cerrahisi işlemleri öncesi dental kaygının günümüzde diş hekimliği alanındaki teknik, farmakolojik ve cerrahi gelişmelere rağmen dikkate değer ölçüde varlığını sürdürdüğünü göstermektedir. Ağız cerrahisi uygulamalarında anksiyete tanımlayıcı/giderici

Makale gönderiliş tarihi: 29 Mayıs 2014; Yayına kabul tarihi: 29 Haziran 2014 *iletişim: Sara Samur Ergüven, Koru Mah. Kavaklı Sok. No: 6 Daire: 43, 06810 Ankara, Türkiye;

e-posta: sara_samur@hotmail.com yöntemlerin uygulanması hasta rahatının artırılması ve cerrahi koşulların iyi hale getirilmesi açısından önem taşımaktadır.

Anahtar Kelimeler: Ağız cerrahisi; dental anksiyete; diş hekimliği

KaynaK Göstermek İçin: Samur Ergüven S, Kılınç Y, Delilbaşı E, Işık B. Bir diş hekimliği fakültesi ağız, diş ve çene cerrahisi kliniğine başvuran hastaların dental kaygı düzeylerinin değerlendirilmesi. Acta Odontol Turc 2015;32(1):7-11

YaYın HAKKI: () 2015 Samur Ergüven ve ark. Bu eserin yayın hakkı Creative Commons Attribution License ile ruhsatlandırımıştır. Sınırsız kullanım, dağıtım ve her türlü ortamda çoğaltım, yazarlar ve kaynağın belirtilmesi kaydıyla serbesttir.

[Abstract in English is at the end of the manuscript]

\section{Giriş}

Diş tedavisi öncesi veya sırasında hastaların deneyimlediği kaygı, eksternal ve internal uyaranlara karşı oluşan fizyolojik aktivasyon ile ilişkili kompleks davranış biçimi olarak tanımlanmaktadır. ${ }^{1}$ Amerika Birleşik Devletlerinde tahmini olarak 23 milyon kişinin korku nedeniyle diş tedavisinden kaçındığı, çeşitli ülkelerde yapılan çalışmalarda ise dental kaygı oranlarının \%4.2 ile \%20.9 aralığında saptandığı ifade edilmiştir. ${ }^{2,3}$

Yaş, cinsiyet, eğitim düzeyi, travmatik diş hekimliği deneyimi, planlanan diş hekimliği tedavisi türü ve diş hekimliğine gitme sıklığı parametreleri ile dental kaygı ilişkisini değerlendiren çok sayıda çalışma mevcuttur. ${ }^{1,4-6}$ Çocukluk döneminde yaşanılan travmatik deneyimler, psikolojik, ailesel faktörler ve sosyal çevre dental kaygının başlangıcı ile ilişkilidir. ${ }^{7-9}$ Dental kaygının diş hekimliği işlemlerinin gerçekleştirilmesi için engel oluşturabileceği ve ağız hastalıkları indisansını artırabileceği bildirilmiştir. ${ }^{10,11}$

Birçok diş hekimliği işlemi öncesi hastalar çeşitli düzeylerde kaygı hissetmekle birlikte, ağız cerrahisi işlemleri en yüksek kaygı seviyesi ile ilişkilendirilmektedir. ${ }^{12-14}$ Ülkemizde yapılan bir çalışmaya göre küçük ağız cerrahisi işlemi uygulanacak hastaların \%30'unda hafif, \%40'ında orta, \%14'ünde yüksek ve \%11'inde çok yüksek düzeyde kaygı seviyeleri saptanmış, hiçbir kaygı hissetmeyen 
hasta oranı ise sadece $\% 5$ olarak bildirilmiştir. ${ }^{15}$ Türkiye'de gerçekleştirilen bir diğer çalışmada ağız cerrahisi öncesi ciddi ve çok ciddi seviyede kaygı oranı sırası ile $\% 15$ ve \%10.8 olarak bildirilmiş, pre-operatif kaygı seviyesi ile ağrı beklentisinin ilişkili olduğu saptanmıştır. ${ }^{16}$

Literatürde ülkemizde gerçekleştirilen çalışmalar olmakla birlikte diş hekimliği fakültesi Ağız, Diş ve Çene Cerrahisi kliniğine başvuran hastalar arasında dental kaygı oranının değerlendirildiği çalışmamızdaki kadar geniş sayıda hasta içeren bir çalışma ile karşılaşılmadı. Bu çalışmanın amacı, Ağız, Diş ve Çene Cerrahisi kliniğine başvuran hastaların dental kaygı oranını ve dental kaygı ile ilişkili olabileceği düşünülen faktörleri değerlendirmektir.

\section{Gereç Ve Yöntem}

Gazi Üniversitesi Tıp Fakültesi Klinik Araştırmalar Etik Kurulundan onay alınmasını takiben, 1 Şubat 2013-1 Ocak 2014 tarihleri arasında Gazi Üniversitesi Diş Hekimliği Fakültesi Ağız, Diş ve Çene Cerrahisi Kliniğine başvuran 18 yaş üzeri 1165 hasta çalışma hakkında bilgilendirilerek yazılı onayları alındı. Anket formunun ilk kısmında demografik verilerin elde edilmesini sağlayan temel sorular ile dental kaygı düzeyini etkileyebileceği düşünülen eğitim düzeyi, ilk diş hekimine gitme yaşı, diş hekimine gitme sıklığı, ağızdaki eksik diş sayısı, geçirilmiş travmatik diş hekimliği deneyimi varlığı ve ağız cerrahisi kliniğine başvuru amacını belirlemeye ilişkin sorular yer aldı. İkinci kısımda ise günümüzde yetişkinlerde dental kaygı düzeyinin belirlenmesinde en sık kullanılan ölçekler arasında bulunan Modifiye Dental Anksiyete Skalası
(MDAS; Tablo 1) yer aldı. ${ }^{17,18}$ MDAS skoru $\geq 19$ değeri yüksek dental kaygı düzeyi olarak değerlendirildi. Anket formlarının doldurulması sonrası elde edilen veriler SPSS veri programına (SPSS Inc., Chicago, IL, ABD) aktarılarak deskriptif yöntemlerle istatistiksel analizleri gerçekleştirildi. Anketlerin doldurulması sonrası hastalara gereken tedavi işlemleri uygulandı. Gerekli durumlarda planlanan cerrahi işlem için ameliyathane randevusu verildi.

\section{BULGULAR}

Çalışmada yer alan 1165 olgunun \%36.1'i ( $n=421)$ erkek, \%63.9'u (n=744) kadın olup, bireylerin yaş ortalaması 34.87'dir. Katılımcıların \%56.7'si evli, \%43.3'ü bekar olarak saptandı. Katılanların \%21.2'si ilkokul ve altı eğitim düzeyindeyken, \%9.5'i ortaokul, \%29'u lise, \%36.7'si üniversite, \%3.6'sı yüksek lisans/doktora mezunudur. Araştırmaya katılanların \%6.4'ü 0-6 yaş aralığında, \%33.6'sı 7-12 yaş aralığında, \%22.7'si 13-18 yaş aralığında, \%37.3'ü 18 yaş ve üzerindeyken, ilk kez diş hekimine gitmiştir. Araştırmaya katılanların \%73'ü sadece bir problem olduğunda diş hekimine gitmekte olup, katılımcıların diş hekimine gitme sıklığını gösteren grafik Şekil 1'de gösterilmiştir.

Araştırmaya katılanların \%33.5'inin hiç eksik dişi yokken, \%42.7'sinin 1-5 arası, \%12.7'sinin 6-10 arası ve $\% 11.2$ 'sinin ise 11 ya da daha çok sayıda eksik dişi bulunmaktadır. Araştırmaya katılanların \%21.3'ünün daha önce diş hekimliği ile ilişkili travmatik bir deneyim yaşamış olduğu, \%78.7'sinin travmatik deneyim yaşamadıkları saptanmıştır.

Tablo 1. Modifiye Dental Anksiyete Skalası (MDAS)

Lütfen aşağıda sıralanmış 5 soru için size en uygun seçeneği işaretleyin.

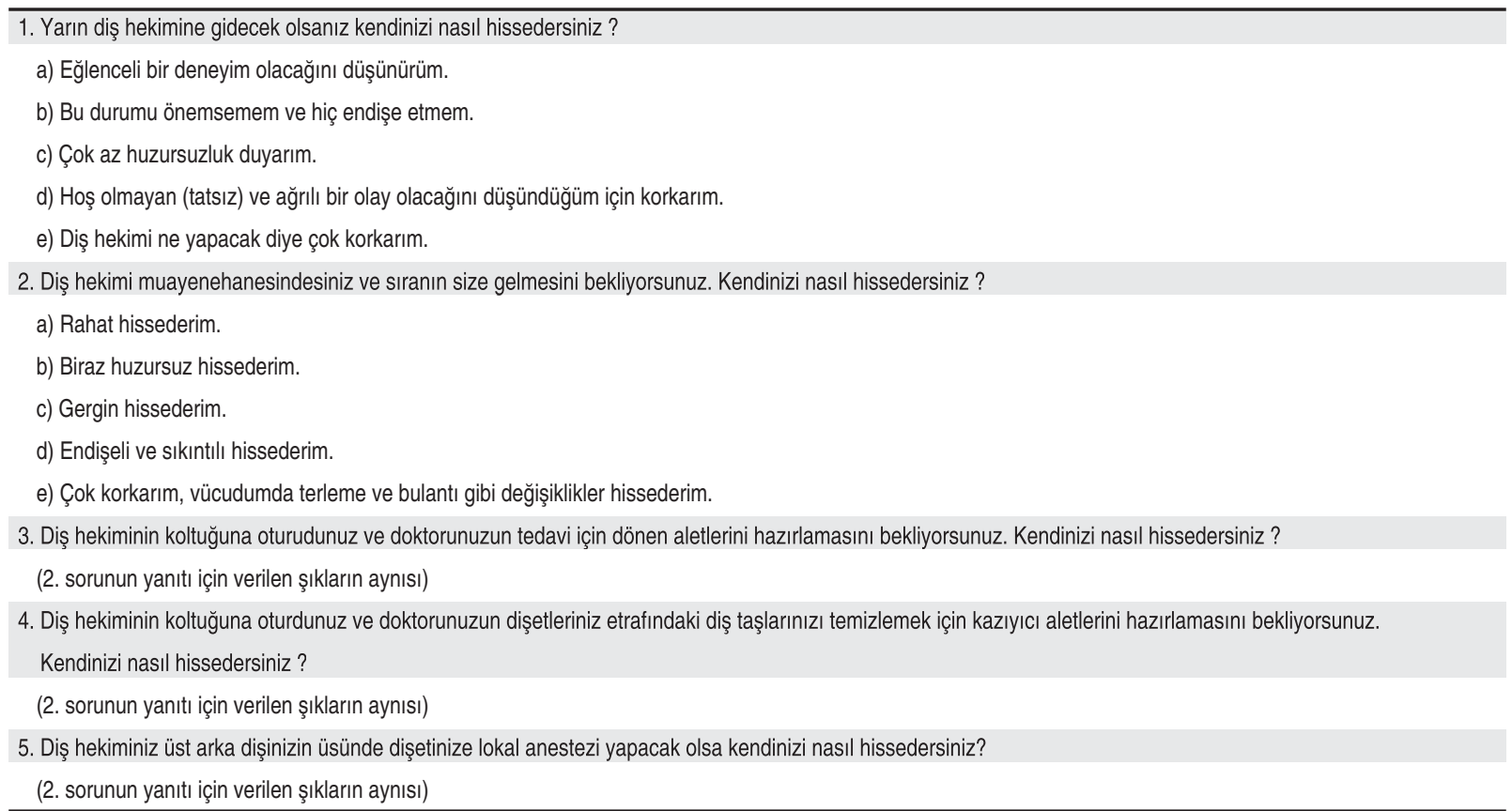




\section{Diş hekimine gitme sıklığı}

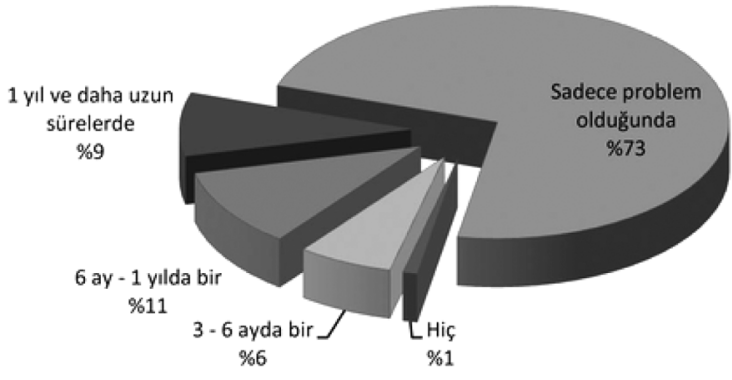

Şekil 1. Katıımcıların diş hekimine gitme sıklığı

Araştırmaya katılanların \%47.3'ü diş çekimi, \%28'i gömülü diş çekimi, \%3'ü implant tedavisi, \%3.7'si temporomandibuler eklem şikayetleri, \%1.4'ü miyofasiyal ağrı, \%16.6'sı ise diğer (apikal rezeksiyon işlemi, preprotetik cerrahi işlem, ağız içi lezyon, sert doku cerrahisi, maksillofasiyal travma, odontojenik enfeksiyon-apse, odontojenik/nonodontojenik lezyon, ortognatik cerrahi ve diğer) amaçlarla kliniğe başvurmuştur (Şekil 2).

Tüm olgular içinde dental kaygıya sahip (MDAS skor değeri $\geq 19$ ) olanların oranı \%14.1 olarak saptanmıştır. Yaş, medeni durum, eğitim düzeyi, diş hekimine ilk gitme yaşı, eksik diş sayısı ve kliniğe başvuru amacı ile dental kaygı arasında anlamlı ilişki saptanmamıştır (sırasıyla $p=0.383, p=0.387, p=0.553, p=0.186, p=0.514$, $\mathrm{p}=0.449$ ). Bununla birlikte; cinsiyet, diş hekimine gitme sıklığı, önceden geçirilmiş travmatik diş hekimliği deneyimi ile dental kaygı arasında ilişki olduğu tespit edilmiştir (hepsi için $p<0.05$; Tablo 2).

\section{TARTIŞMA}

Diş hekimliği işlemlerine yönelik kaygı; ağız sağlığı ve ağız sağlığı ilişkili yaşam kalitesi üzerine olumsuz etki etmekte olup sıklıkla araştırmalara konu olmaktadır. ${ }^{19-21}$ Günümüzde yetişkinlerde dental kaygı düzeyinin belirlenmesinde sıklıkla kullanılan dental kaygı ölçekleri Corah Dental Anksiyete Skalası (CDAS) ve Modifiye Dental Anksiyete Skalası (MDAS) olarak bildirilmektedir. ${ }^{17,18}$
Dental kaygı düzeyinin belirlenmesini amaçlayan CDAS, Corah tarafından 1969 yılında tanıtılmıştır. ${ }^{22}$ Toplam dört adet sorudan oluşmakta olup, verilen yanıtların sayısal olarak karşılıklarının toplamı kişinin dental kaygı düzeyi hakkında bilgi vermektedir. Corah Dental Anksiyete Skalası değerlendirilmesinde skor ile dental kaygı arasında doğru orantı ilişkisine dayanan bir sonuç elde edilir.

Corah Dental Anksiyete Skalası uygulama kolaylığına ve yeterli psikometrik özelliklere sahip bir değerlendirme ölçeği olmasına rağmen; lokal anestezi enjeksiyonu ile ilgili bir değerlendirme içermemektedir. Bu çalışmada tercih edilen MDAS ise CDAS'a ağız içi enjeksiyona ilişkin kaygı seviyesini ölçen sorunun ekIenmesi ile oluşturulmuş olup, puanlama 5-25 arasında değişmektedir. ${ }^{17,23}$

İngiltere'de 1392 katılımcı üzerinde gerçekleştirilen çalışmada, MDAS'ın kaygı seviyesi yüksek ve kaygıya sahip olmayan hastalarda yüksek güvenilirlik ve geçerliliğe sahip olduğu bildirilmiştir. ${ }^{24}$ Türk toplumu üzerinde yapılan çalışmalarda da MDAS'ın geçerli ve güvenilir olduğu belirlenmiştir. ${ }^{25,26}$ Modifiye Dental Anksiyete Skalası'nın Türk hastalar üzerinde güvenilirlik ve geçerliliğinin değerlendirildiği çalışmada yazarlar, çalışmamızda olduğu gibi kesiş noktası olarak $\geq 19$ değeri alındığında, skalanın uygun hassasiyete ve özgüllüğe sahip olduğunu bildirmişlerdir. ${ }^{25}$

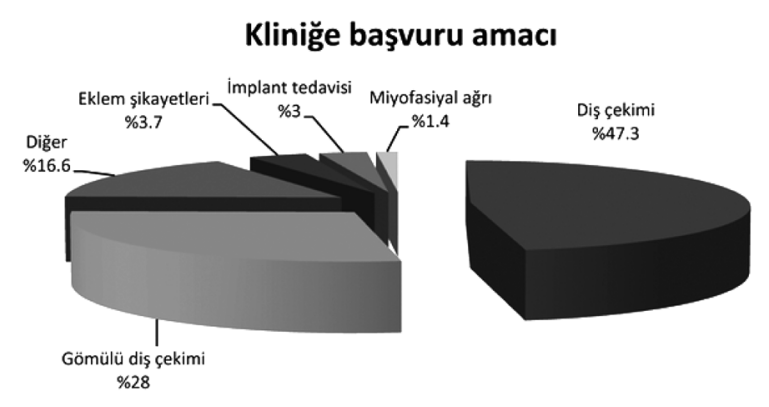

Şekil 2. Katıımcıların kliniğe başvuru nedenleri

Tablo 2. Cinsiyet, diş hekimine gitme sıkı̆̆ı ve önceden geçirilmiş travmatik diş hekimliği deneyimi ile yüksek dental kaygı ilişkisi [\%sıklık, (n)]

\begin{tabular}{|c|c|c|c|c|}
\hline & & MDAS $<19$ & MDAS $\geq 19$ & p değeri \\
\hline \multirow[t]{2}{*}{ Cinsiyet } & Erkek & $\% 95.5(402)$ & $\% 4.5(19)$ & \multirow{2}{*}{$p<0.05$} \\
\hline & Kadın & $\% 80.5(599)$ & $\% 19.5(145)$ & \\
\hline \multirow[t]{5}{*}{ Diş hekimine gitme sıklığı } & Hiç & $\% 58.3(7)$ & $\% 41.7(5)$ & \multirow{5}{*}{$p<0.05$} \\
\hline & 3-6 ayda bir & $\% 93.5(72)$ & $\% 6.5(5)$ & \\
\hline & 6ay-1yılda bir & $\% 88.2(112)$ & $\% 11.8(15)$ & \\
\hline & 1 yıl ve daha uzun sürelerde & $\% 86.4(89)$ & $\% 13.6(14)$ & \\
\hline & Sadece bir problem olduğunda & $\% 85.2(721)$ & $\% 14.8(125)$ & \\
\hline \multirow[t]{2}{*}{ Travmatik diş hekimliği deneyimi varlığı } & Var & $\% 75.7(187)$ & $\% 24.3(60)$ & \multirow{2}{*}{$p<0.05$} \\
\hline & Yok & $\% 88.6(811)$ & $\% 11.4(104)$ & \\
\hline
\end{tabular}


Bu çalışmaya katılan hastaların \% 14.1 'inde yüksek dental kaygı saptanmıştır. Türkiye'de MDAS kullanılarak gerçekleştirilen bir diğer çalışmada dental kaygı oranı \%8.8 olarak bildirilmiştir. ${ }^{25}$ Ingiltere'de çalışmamızda olduğu gibi yetişkin bireylere uygulanan MDAS ile dental kaygı oranı değerlendirilmiş, dental kaygı seviyesi \%11.6 oranında saptanmıştır. ${ }^{23}$ Samur-Ergüven ve ark. ${ }^{4}$ diş hekimliği fakültesi birinci sınıf öğrencileri ile son sınıf öğrencilerinin dental kaygı düzeylerini karşılaştırmalı olarak değerlendirdikleri çalışmada, dental kaygıya sahip olan öğrenci oranını 1. sınıf öğrencilerinde \%10.4, 5. sınıf öğrencilerinde ise \%1.8 olarak bildirmiştir. $\mathrm{Ng}$ \& Leung $^{20}$ Hong Kong'da yaşayan bireylerde dental kaygı oranını \%10.5 olarak saptamışlardır.

Çalışmamızdaki dental kaygı oranının, belirtilen diğer çalışmalardan ${ }^{4,20,23,25}$ daha yüksek olarak saptanmasının ağız cerrahisi işlemlerinin diğer diş hekimliği işlemlerine göre daha yüksek dental kaygıyla ilişkilendirilmesi ile ilgili olduğu düşünülmektedir.

Birçok diş hekimliği işlemi öncesi hastalar çeşitli düzeylerde kaygı hissetmekle birlikte, cerrahi sonrası ağrı, kanama, şişlik, ağız açıkığında azalma ve normal günlük aktivitelerde kısıtlanma ile bağlantılı bulunan ağız cerrahisi işlemleri en yüksek kaygı seviyesi ile ilişkilendirilmektedir. ${ }^{12-14}$

Ağız cerrahisi ve dental kaygı ilişkisinin farklı yönlerden değerlendirildiği çalışmalar bulunmaktadır. Eli ve ark. ${ }^{27}$ implant yerleşimi öncesi, sırası ve sonrasında dental ve durumluk kaygı düzeyinin ağrı yanıtı üzerine etkisini değerlendirdikleri çalışmada kaygı seviyesinin kadınlarda erkeklere göre daha fazla olduğunu ve durumluk kaygı düzeyinin ağrı yanıtı ile ilişkili olduğunu bildirmişlerdir.

Ayaktan gerçekleştirilen ağız cerrahisi uygulamaları içerisinde üçüncü molar diş çekiminin en çok kaygı oluşturan işlem olduğu bildirilmiş ve bu tür cerrahi ihtiyacı olan hastalarda davranışsal durumun iyileştirilmesinin tüm tedavi işlemine yönelik rahatın arttırıması açısından önemli olduğu ifade edilmiştir. ${ }^{28}$ Bununla birlikte üçüncü molar dişin gömülü ya da gömülü olmayan pozisyonda olmasının dental kaygı skorları üzerine etkisinin olmadığı bildirilmiştir. ${ }^{6}$

Çalışmamızda hastalar kliniğe başvuru amacı açısından değerlendirildiğinde; gömülü diş çekimi ve miyofasiyal ağrı grupları içerisinde yüksek dental kaygı oranları daha yüksek saptanmış olmakla birlikte, diğer başvuru amaçları ile aralarında istatistiksel olarak belirgin fark yoktur $(p=0.449)$.

Wilson ve ark. ${ }^{10}$ ağız cerrahisinin genellikle kaygı ile ilişkili olduğunu ancak lokal anestezi ile birlikte kullanılacak bilinçli sedasyon uygulamalarının hastaların oral cerrahiye yönelik kaygı ve ağrı skorlarında önemli ölçüde düşüş sağlayarak ağız sağlığına katkıda bulunabileceğini bildirmiştir.

Muğlalı \& Kömerik ${ }^{16}$ yapmış oldukları çalışmada ağız cerrahisi öncesi ve sonrasında kaygıya etki eden faktörleri değerlendirmiş; çenede yorgunluk oluşması ve ağızda sıvı birikimini hastaların kaygı duyduğu durumlar olarak saptamışlardır. Ağız cerrahisi uygulamalarında bu hususlara dikkat edilmesinin hastaların tedavilerini daha kolay hale getirebileceğini ifade etmişlerdir. Bir diğer çalışmada ağız cerrahisi geçirecek hastalara operasyon öncesi, operasyona ve cerrahi sonrası iyileşme dönemine ilişkin bilgilendirme yapılmasının kaygı seviyesinde ciddi düzeyde azalma oluşturabileceği bildirilmiştir. ${ }^{11}$

Ağız cerrahisinde kullanılan gelişmiş ekipmanların ve sedasyon uygulamalarının dental kaygıyı azaltmada etkili olabileceği ve tedavinin kabul edilebilirliğini artırabileceği gösterilmiştir. ${ }^{29,30}$ Geleneksel enstrümanlar ya da Er:YAG lazer uygulanarak gerçekleştirilen apikal rezeksiyon işlemlerinde istatistiksel olarak anlamlı olmasa da lazer kullanılan hasta grubunda geleneksel gruba kıyasla daha düşük kaygı seviyeleri saptanmıştır. ${ }^{31}$

Ağız cerrahisi ve kaygı ilişkisinin değerlendirildiği bir diğer çalışmada cinsiyet, geçmiş dental tedavi tecrübesi ve kişilik durumu kaygı ile ilişkilendirilmiş olup, en az kaygı seviyesinin elde edilmesinin hekim ve hasta için tedavi işleminin rahatığını artıracağı ifade edilmiştir. ${ }^{15}$

Çalışmamızda dental kaygının yaş, medeni durum, eğitim düzeyi parametreleri ile anlamlı ilişkisi saptanmazken; cinsiyet, daha önce geçirilmiş travmatik deneyim varlığı ve diş hekimine gitme sıklığı, dental kaygı ile ilişsili olarak belirlenmiştir. Yüksek dental kaygıya sahip olma oranı kadınlarda erkek cinsiyete göre 5.12 kat, geçmişte travmatik diş hekimliği deneyimi olanların olmayanlara göre 2.5 kat, hiç diş hekimine gitmeyen bireylerde 3-6 ayda bir gidenlere göre 10.28 kat daha fazla olarak saptanmıştır.

\section{SONUÇ}

Araştırma sonucunda ağız, diş ve çene cerrahisi kliniğine başvuran hastaların yaklaşık 1/7'sinin yüksek dental kaygı düzeyine sahip olduğu saptanmıştır. Cinsiyet, diş hekimine gitme sıklığı ve geçirilmiş travmatik deneyim, yüksek dental kaygı oranı ile ilişkili olarak belirlenmiştir. Bu sonuçlar ışığında, dental kaygının toplumda yadsınamayacak ölçüde varlığını sürdürdüğü; hastalarda ağız cerrahisi girişimleri öncesi tedavi kabul edilebilirliğinin sağlanması amacıyla gerekli durumlarda psikolojik ve girişimsel yaklaşımların uygulamasının yarar sağlayabileceği kanısındayız.

Çıkar çatışması: Yazarlar bu çalışmayla ilgili herhangi bir çıkar çatışmalarının bulunmadığını bildirmişlerdir. 


\section{KAYNAKLAR}

1. López-Jornet $P$, Camacho-Alonso F, Sanchez-Siles M. Assessment of general pre and postoperative anxiety in patients undergoing tooth extraction: a prospective study. Br J Oral Maxillofac Surg 2014;52:18-23. 2. Dionne RA, Gordon SM, McCullagh LM, Phero JC. Assessing the need for anesthesia and sedation in the general population. J Am Dent Assoc 1998;129:167-73.

3. Chanpong B, Haas DA, Locker D. Need and demand for sedation or general anesthesia in dentistry: a national survey of the Canadian population. Anesth Prog 2005;52:3-11.

4. Samur-Ergüven $S$, Işık $B, K$ Kılınç $Y$. Diş hekimliği fakültesi birinci sınıf öğrencileri ile son sınıf öğrencilerinin dental kaygı-korku düzeylerinin karşılaştırmalı olarak değerlendirilmesi. Acta Odontol Turc 2013;30:70-6.

5. Nicolas E, Collado V, Faulks D, Bullier B, Hennequin M. A national cross-sectional survey of dental anxiety in the French adult population. BMC Oral Health 2007;7:12.

6. Yusa H, Onizawa K, Hori M, Takeda S, Takeda H, Fukushima S, et al. Anxiety measurements in university students undergoing third molar extraction. Oral Surg Oral Med Oral Pathol Oral Radiol Endod 2004;98:23-7.

7. Locker D, Thomson WM, Poulton R. Psychological disorder, conditioning experiences, and the onset of dental anxiety in early adulthood. J Dent Res 2001;80:1588-92.

8. Locker D, Poulton R, Thomson WM. Psychological disorders and dental anxiety in a young adult population. Community Dent Oral Epidemiol 2001;29:456-63.

9. Skaret E, Raadal M, Berg E, Kvale G. Dental anxiety among 18-yrolds in Norway. Prevalence and related factors. Eur J Oral Sci 1998;106:835-43.

10. Wilson TD, McNeil DW, Kyle BN, Weaver BD, Graves RW. Effects of conscious sedation on patient recall of anxiety and pain after oral surgery. Oral Surg Oral Med Oral Pathol Oral Radiol 2014;117:277-82.

11. Ng SK, Chau AW, Leung WK. The effect of pre-operative information in relieving anxiety in oral surgery patients. Community Dent Oral Epidemiol 2004;32:227-35.

12. Hermes D, Matthes M, Saka B. Treatment anxiety in oral and maxillofacial surgery. Results of a German multi-centre trial. J Craniomaxillofac Surg 2007;35:316-21.

13. Stabholz A, Peretz B. Dental anxiety among patients prior to different dental treatments. Int Dent J $1999 ; 49: 90-4$.

14. Wong M, Lytle WR. A comparison of anxiety levels associated with root canal therapy and oral surgery treatment. J Endod 1991;17:4615.

15. Muğlalı M, Kömerik N. Ağız cerrahisi ve anksiyete. Cumhuriyet Üniversitesi Diş Hekimliği Fakültesi Dergisi 2005;8:83-8.

16. Muglali M, Komerik N. Factors related to patients' anxiety before and after oral surgery. J Oral Maxillofac Surg 2008;66:870-7.

17. Armfield JM. How do we measure dental fear and what are we measuring anyway? Oral Health Prev Dent 2010;8:107-15.

18. Dailey YM, Humphris GM, Lennon MA. The use of dental anxiety questionnaires: a survey of a group of UK dental practitioners. Br Dent J 2001;190:450-3.

19. Gisler V, Bassetti R, Mericske-Stern R, Bayer S, Enkling N. A crosssectional analysis of the prevalence of dental anxiety and its relation to the oral health-related quality of life in patients with dental treatment needs at a university clinic in Switzerland. Gerodontology 2012;29:e290-6.

20. Ng SK, Leung WK. A community study on the relationship of dental anxiety with oral health status and oral health-related quality of life. Community Dent Oral Epidemiol 2008;36:347-56.

21. Vermaire $\mathrm{JH}$, de Jongh $\mathrm{A}$, Aartman $\mathrm{IH}$. Dental anxiety and quality of life: the effect of dental treatment. Community Dent Oral Epidemiol 2008;36:409-16.

22. Corah NL.Development of a dental anxiety scale. J Dent Res 1969;48:596.

23. Humphris GM, Dyer TA, Robinson PG. The modified dental anxiety scale: UK general public population norms in 2008 with further psychometrics and effects of age. BMC Oral Health 2009;9:20.

24. Humphris GM, Morrison T, Lindsay SJ. The Modified Dental Anxiety Scale: validation and United Kingdom norms. Community Dent Health 1995;12:143-50.
25. Ilgüy $D$, Ilgüy $M$, Dinçer $S$, Bayirli G. Reliability and validity of the Modified Dental Anxiety Scale in Turkish patients. J Int Med Res 2005;33:252-9.

26. Tunc EP, Firat D, Onur OD, Sar V. Reliability and validity of the Modified Dental Anxiety Scale (MDAS) in a Turkish population. Community Dent Oral Epidemiol 2005;33:357-62.

27. Eli I, Schwartz-Arad D, Baht R, Ben-Tuvim H. Effect of anxiety on the experience of pain in implant insertion. Clin Oral Implants Res 2003;14:115-8.

28. Sirin $Y$, Humphris G, Sencan S, Firat D. What is the most fearful intervention in ambulatory oral surgery? Analysis of an outpatient clinic. Int J Oral Maxillofac Surg 2012;41:1284-90.

29. Zhang G, Hou R, Zhou H, Kong L, Ding Y, Qin R, et al. Improved sedation for dental extraction by using video eyewear in conjunction with nitrous oxide: a randomized, controlled, cross-over clinical trial. Oral Surg Oral Med Oral Pathol Oral Radiol 2012;113:188-92.

30. Berge TI. Acceptance and side effects of nitrous oxide oxygen sedation for oral surgical procedures. Acta Odontol Scand 1999;57:201-6. 31. Ugurlu F, Cavus O, Kaya A, Sener CB. Evaluation of dental anxiety in patients undergoing dentoalveolar surgery with laser treatment. Photomed Laser Surg 2013;31:169-73.

\section{Evaluation of the dental anxiety levels of patients attending the oral and maxillofacial surgery clinic in a dental faculty}

\section{Abstract}

OBJECTIVE: The aim of this study was to assess the dental anxiety levels of patients attending the Oral and Maxillofacial Surgery clinic in a dental faculty and to evaluate the associated factors that might be related with the dental anxiety.

MateriALs ANd Method: Questionnaires were applied to patients attending the Department of Oral and Maxillofacial Surgery Clinic, Faculty of Dentistry, Gazi University between February 1, 2013 and January 1, $2014(n=1165)$. The questionnaire included a Modified Dental Anxiety Scale (MDAS) and questions that might be related with dental anxiety. Participants whose MDAS score value was $\geq 19$ were considered as highly anxious. Data which also included the participants' demographic values were transferred to a statistical software and the results were examined through descriptive methods.

RESULTS: High dental anxiety level among patients participated in the study amounted to a rate of $14.1 \%$. Dental anxiety was not related to age, marital status, educational level, firsttime-dental visit-age, number of lacking teeth, and reason of the dental visit $(p>0.05)$. However, the indicators gender, previous traumatic experience and dental visit frequency were significantly related to dental anxiety $(p<0.05)$.

ConcLusion: Results of the present study showed that dental anxiety before oral surgical procedures is still prevalent despite technical, pharmacological and surgical advances in dentistry. Implementation of anxiety identification/reducing procedures in the oral surgery practice is of great importance to increase patient comfort and optimize surgical circumstances.

KEYWORDS: Dental anxiety; dentistry; oral surgery 